\title{
Teaching Creativity Across Disciplines at Ontario Universities
}

\author{
Elizabeth Marquis and Jeremy A. Henderson \\ McMaster University
}

\begin{abstract}
While a wide variety of publications have suggested that the development of student creativity should be an important objective for contemporary universities, information about how best to achieve this goal across a range of disciplinary contexts is nonetheless scant. The present study aimed to begin to fill this gap by gathering data (via an electronic survey instrument) about how the teaching and learning of creativity are perceived and enacted by instructors in different disciplines at Ontario universities. Results indicated points of both convergence and divergence between respondents from different fields in terms of their understandings of the place of creativity within courses and programs, and in terms of strategies they reported using to enable creativity in their students. We discuss the implications of these findings, including the ways in which the data speak to ongoing debates about the role of disciplines within teaching, learning, and creativity more broadly.
\end{abstract}

\section{Résumé}

Bien qu'une grande diversité de publications suggère que le développement de la créativité chez l'étudiant devrait être un objectif important pour les universités contemporaines, l'information quant à la meilleure façon d'atteindre un tel objectif parmi tout un éventail de contextes disciplinaires demeure insuffisante. La présente étude vise à commencer à combler cet écart en rassemblant des données relatives aux façons dont l'enseignement et l'apprentissage de la créativité sont perçus et mis en œuvre par les instructeurs de diverses disciplines auprès des universités de l'Ontario. Les résultats ont indiquéà la fois des points de convergence et de divergence entreles répondants provenant de secteurs différents en ce qui a trait à leur compréhension de la place de la créativité dans les cours et les programmes, et en ce qui a trait 
aux stratégies qu'ils déclarent utiliser pour susciter la créativité chez leurs étudiants. Nous discutons des implications de ces résultats, y compris de la façon dont les données se révèlent aux débats actuels qui portent sur le rôle des disciplines et, de façon plus générale, sur l'enseignement, l'apprentissage et la créativité.

\section{Introduction}

There is a pressing need for institutions of higher education to develop creativity in their students, regardless of the students' discipline of study. As Mihaly Csikszentmihalyi has suggested, "it takes creativity not to be blinded by the trappings of stability, to recognize the coming changes, anticipate their consequences, and thus perhaps lead them in a desirable direction" (2006, p. xviii). Many have noted that the challenges that future leaders and professionals will face are extremely complex and will be insurmountable if we are equipped with only what is presently known (Craft, 2006; McWilliam, 2008; Shaheen, 2010; Smith-Bingham, 2006). If these challenges are to be met, some scholars argue, educational structures will have to undergo a "dramatic transformation" in order to facilitate the development of students' creative capacities (Seltzer \& Bentley, 1999).

In Ontario, these ideas have been reinforced by the provincial government, which stated in a 2012 report that "Ontario's colleges and universities will drive creativity, innovation, knowledge, and community engagement through teaching and research" (Ontario Ministry of Training, Colleges, and Universities, 2012, p. 7). While such statements suggest broad support for enhancing creativity in Ontario universities, the ways in which this imperative plays out in actual institutions remains to be seen. At present, there is little research examining this issue in the Ontario context. Scholarship from other countries, however, identifies a number of areas of potential concern. Some authors argue, for instance, that the coupling of creativity with the neoliberal "impact agenda" in governmental discourses has ultimately stifled curiosity and risk-taking and thus effectively reduced creativity in research (Walsh, Anders, Hancock, \& Elvidge, 2013). Of more immediate relevance to the question of facilitating students' creative abilities, other work suggests that creativity occupies a comparatively minor place in day-to-day considerations of university teaching and learning-in spite of its growing presence in educational discourse (Jackson \& Shaw, 2006; Kleiman, 2008)-and that it is only rarely incorporated into courses and curricula as an explicit, central, and intentionally facilitated learning outcome (Jackson, 2008; Petocz, Reid, \& Taylor, 2009). Should these findings hold in the Ontario context, the capacity of the province's universities to develop student creativity is seriously circumscribed. With this in mind, the present study seeks to understand the perspectives of Ontario's university instructors with respect to creativity and the position it occupies in their classrooms.

Of particular interest here is the question of whether or not instructors' disciplinary identities impinge upon their conceptions of creativity and the ways in which they seek to teach it. ${ }^{1}$ While common definitions of creativity hinge on the combination of novelty and usefulness (e.g., Mumford, 2003; Plucker \& Makel, 2010; Zacher \& Johnson, 2014) and/or emphasize concepts such as originality, imagination, exploration, transformation, and synthesis (Jackson, 2006; Kleiman, 2008), many scholars nonetheless point out that 
these generic characterizations can only be understood and actualized within specific domains (Csikszentmihalyi, 1999; Jackson \& Shaw, 2006; Kaufman \& Baer, 2005). That is, for an idea, product, or process to be considered creative, it must add to or play out within a particular field in a manner that practitioners of that field see as distinctive, original, and worthwhile. This, of course, means that disciplinary norms, values, and epistemologies can exert a palpable effect on assessments of creativity within different domains (Reid \& Petocz, 2004). Moreover, some research indicates that individuals from various disciplines may have distinctive conceptions of creativity and its relevance to their work (Jackson \& Shaw, 2006; Walsh et al., 2013), and that many people operate according to an "art bias" that positions creativity as especially pertinent to the arts in particular (Glăveanu, 2014; Oliver, Shah, McGoldrick, \& Edwards, 2006). To the extent that these assertions are true, instructors from different academic domains might be differentially likely to attempt to foster creativity in their students, with faculty in arts-related fields viewing this as a priority more commonly than others.

In spite of these findings about disciplinary difference, other research indicates that academics in fact hold similar conceptions of creativity regardless of the field in which they work (Fryer, 2006), or focuses on shared elements of understanding while acknowledging that these inevitably play out within particular disciplinary frames (Edwards, McGoldrick, \& Oliver, 2006). Much of this work also contests the notion that creativity is the specific purview of the arts, pointing out that individuals across academic domains understand creativity as essential to their fields (e.g., Edwards et al., 2006). Given these divergent findings, further research into the impact of discipline on instructors' understandings of creativity and of its place in their teaching is merited.

The potential impact of discipline on the ways in which creativity might be fostered effectively in students is also a pressing question about which there remains much debate. Existing research has suggested that faculty in different fields tend to use varying approaches to teaching (Lindblom-Ylänne, Trigwell, Nevgi, \& Ashwin, 2006; Neumann, Parry, \& Becher, 2002) and that disciplinary and departmental cultures create specific "teaching and learning regimes" (TLRs) that shape the ways in which educational activities are understood and enacted by members of those cultures (Fanghanel, 2013; Roxå \& Mårtensson, 2008; Trowler, 2008). Given other studies that illustrate the central place of disciplinary affiliation within academic identities (Åkerlind, 2005; Henkel, 2005), these TLRs have the potential to be especially potent predictors of pedagogical practices (Mårtensson, Roxå, \& Olsson, 2011), including those tailored to the development of students' creativity. Along these lines, Norman Jackson has positioned "align[ing] creativity with discipline culture and needs" as his first "principle for constructing teaching and learning environments to promote students' creativity" (Jackson, 2006, p. 205).

At the same time, however, other recent scholarship asserts that the determining power of disciplines has been overstated. Trowler (2013), for instance, argues that "strong essentialist" conceptualizations ignore the actual heterogeneity and flexibility of academic fields, while Brew (2008) presents findings that question the notion that scholars hold singular disciplinary identifications that guide their actions and behaviours. Likewise, other critics of discipline-focused approaches to teaching and learning note that-in spite of perceptions to the contrary-principles of good pedagogy are more often than not generalizable across a wide range of domains (Wareing, 2009; Young, 2010). Many strate- 
gies that have been advanced for developing creativity specifically are likewise positioned either explicitly or implicitly as discipline-generic (Baillie, 2006; Beghetto, 2010; Fryer, 2006; Zacher \& Johnson, 2014). Typically, however, authors advocating general approaches do not go so far as to abandon considerations of discipline completely. Indeed, some proponents of generic models nonetheless acknowledge that many faculty perceive their fields as distinctive (Wareing, 2009), and thus allow that engagement in teaching and learning might be to some extent bound up in disciplinary discourses.

If Ontario universities are to meet their share of the demand to develop student creativity, then, it may be necessary to understand how instructors think about the teaching of creativity within the confines of their fields. Moreover, if, as some have argued (e.g., Healey, 2000; Manathunga, 2006; McLean, 2009), successful development efforts aimed at enhancing teaching and learning need to be grounded in disciplinary language and contexts, understanding current disciplinary discourses about creativity is a necessary first step to achieving enhanced creative outcomes for students. At the same time, advocates of discipline-general approaches to teaching and learning remind us that there may be much about teaching creativity that cuts across disciplinary boundaries. This range of considerations was corroborated in a pilot study (Marquis \& Vajoczki, 2012), which indicated that faculty members at one Ontario university understand and attempt to teach creativity in ways that are both discipline-general and discipline-specific. Building on this previous work, which involved only a small number of instructors, this study seeks to examine the ways in which faculty from a range of disciplines at Ontario universities define, value, and teach creativity. By understanding faculty attitudes and practices regarding creativity in their fields, we hope to shed further light on the debates outlined above, examine their applicability in the Ontario context, and inform further research on the development of student creativity within and across disciplines.

\section{Research Methodology and Participants}

In order to gather a wide range of perspectives about the teaching and learning of creativity across disciplines in Ontario's universities, an electronic survey instrument containing forced-choice, Likert-scale, and open-ended questions was sent (following ethics approval) to approximately 6,600 full-time instructors at eight Ontario universities (University of Guelph, McMaster University, OCAD University, Queen's University, Trent University, University of Ontario Institute of Technology, University of Waterloo, University of Western Ontario). These institutions were selected due to their diversity in terms of size, location, and type of program offerings. By collecting data from these particular institutions, this study aims to provide a cross-sectional understanding of how Ontario's faculty members understand creativity and foster it in their classrooms. While the majority of participating universities were chosen strictly based on the criteria listed above, OCAD University was also selected due to its institutional emphasis on creativity, as demonstrated by its mission statement: "to challenge each student to find a unique voice within a vibrant and creative environment” (OCAD University, 2013).

The first section of the survey instrument collected demographic information, including institution, home department, gender, and career length. In the second section, participants were asked to provide definitions of creativity and to answer questions about (i) the importance of creativity within their disciplines and (ii) their strategies for helping 
students develop their creative capacities. The questions were adapted from the set used by the researchers in the aforementioned pilot study (Marquis \& Vajoczki, 2012), which itself included questions similar to those reported by Jackson and Shaw (2006).

The electronic survey was made available for two weeks in June 2012. Following data collection and cleaning, basic descriptive statistics were computed for the Likert-style and forced-choice questions, and relevant tests comparing responses by discipline (KruskalWallis and chi-squared) were run using SPSS software. Open-ended survey questions were analysed using a brand of qualitative content analysis based on constant comparison (Merriam, 2009). Participant responses to these questions were first examined in an open coding phase, wherein relevant units of meaning in the data were noted and highlighted. These were subsequently grouped and collapsed into preliminary, higher-order categories as appropriate, which were in turn checked against the original responses to ensure that the code tree was consistent with the data. Where relevant, the number of responses in each category was then calculated, and descriptive statistics and chi-squared tests were run to examine the distribution of responses across disciplines.

During the two-week window in which the survey was active, 658 people completed it (response rate $=10 \%$ ). Of these respondents, 613 specified both their home institution and their discipline, and thus their responses were used in the analysis. The 45 submitted surveys that did not include answers to these two questions were not used in any calculations. All responses were voluntary (participants could skip questions if they chose to do so) and anonymous. The response rates for each of the eight institutions surveyed ranged from 7.0\% (Queen's, University of Ontario Institute of Technology) to 11.6\% (OCAD University). See Table 1 for the institutional breakdown of respondents.

Table 1

Institutional Breakdown of Respondents

\begin{tabular}{lccc}
\hline Institution & $\begin{array}{c}\text { Number } \\
\text { of responses }\end{array}$ & $\begin{array}{c}\text { Percentage of } \\
\text { total responses }\end{array}$ & $\begin{array}{c}\text { Institutional } \\
\text { response rate }\end{array}$ \\
\hline McMaster University & 157 & 25.6 & 10.5 \\
University of Western Ontario & 115 & 18.8 & 9.4 \\
Queen's University & 96 & 15.7 & 7.0 \\
University of Waterloo & 105 & 17.1 & 8.5 \\
University of Guelph & 77 & 12.6 & 10.2 \\
University of Ontario Institute of Technology & 14 & 2.3 & 7.0 \\
Trent University & 32 & 5.2 & 10.9 \\
OCAD University & 17 & 2.8 & 11.6 \\
\hline
\end{tabular}

Participants were asked to self-report their disciplines; the researchers then categorized their responses into broader discipline areas for the purposes of comparison. Some reported disciplines (e.g., law, education, and interdisciplinary fields) did not fit clearly into any larger category of sufficient numbers, so they were placed together in an "other" category. Table 2, below, shows the breakdown of respondents by discipline. 
Table 2

Discipline breakdown of respondents

\begin{tabular}{|c|c|c|}
\hline $\begin{array}{l}\text { Discipline (broad) } \\
\text { Discipline (narrow) }\end{array}$ & $\begin{array}{c}\text { Number of } \\
\text { responses }\end{array}$ & $\begin{array}{c}\text { Percentage of total } \\
\text { responses }\end{array}$ \\
\hline Art/Design/Performance & 42 & 6.9 \\
\hline Art & 10 & 1.6 \\
\hline Design & 8 & 1.3 \\
\hline Drama & 5 & 0.8 \\
\hline Music & 13 & 2.1 \\
\hline Subdiscipline Not Specified & 6 & 1.0 \\
\hline Business & 33 & 5.4 \\
\hline Accounting and Finance & 3 & 0.5 \\
\hline Business - Other & 2 & 0.3 \\
\hline Subdiscipline Not Specified & 28 & 4.6 \\
\hline Engineering & 64 & 10.4 \\
\hline Architecture & 7 & 1.1 \\
\hline Chemical/Biochemical Engineering & 7 & 1.1 \\
\hline Computer Science & 24 & 3.9 \\
\hline Engineering Physics & 4 & 0.7 \\
\hline Mechanical/Materials Engineering & 6 & 1.0 \\
\hline Systems Engineering & 3 & 0.5 \\
\hline Engineering - Other & 3 & 0.5 \\
\hline Subdiscipline Not Specified & 10 & 1.6 \\
\hline Health Sciences & 159 & 25.9 \\
\hline Epidemiology, Biostatistics, Public Health & 12 & 2.0 \\
\hline Medicine & 69 & 11.3 \\
\hline Nursing & 26 & 4.2 \\
\hline Nutrition & 5 & 0.8 \\
\hline Occupational Therapy & 5 & 0.8 \\
\hline Optometry & 7 & 1.1 \\
\hline Rehabilitation Therapy & 8 & 1.3 \\
\hline Veterinary Medicine & 5 & 0.8 \\
\hline Health Sciences - Other & 6 & 1.0 \\
\hline Subdiscipline Not Specified & 16 & 2.6 \\
\hline
\end{tabular}




\begin{tabular}{|c|c|c|}
\hline $\begin{array}{l}\text { Discipline (broad) } \\
\text { Discipline (narrow) }\end{array}$ & $\begin{array}{l}\text { Number of } \\
\text { responses }\end{array}$ & $\begin{array}{c}\text { Percentage of total } \\
\text { responses }\end{array}$ \\
\hline Humanities & 76 & 12.4 \\
\hline English & 27 & 4.4 \\
\hline French & 8 & 1.3 \\
\hline History & 11 & 1.8 \\
\hline Languages & 13 & 2.1 \\
\hline Philosophy & 13 & 2.1 \\
\hline Humanities - Other & 3 & 0.5 \\
\hline Subdiscipline Not Specified & 1 & 0.2 \\
\hline Science & 140 & 22.8 \\
\hline Agriculture & 6 & 1.0 \\
\hline Biology & 35 & $5 \cdot 7$ \\
\hline Chemistry & 15 & 2.4 \\
\hline Geography/Earth \& Environmental Science & 25 & 4.1 \\
\hline Kinesiology & 5 & 0.8 \\
\hline Mathematics and Statistics & 20 & $3 \cdot 3$ \\
\hline Physics & 7 & 1.1 \\
\hline Planning & 9 & 1.5 \\
\hline Psychology & 17 & 2.8 \\
\hline Science - Other & - & - \\
\hline Subdiscipline Not Specified & 1 & 0.2 \\
\hline Social Sciences & 74 & 12.1 \\
\hline Anthropology & 7 & 1.1 \\
\hline Communication, Information, Media Studies & 10 & 1.6 \\
\hline Economics & 12 & 2.0 \\
\hline Political Science & 14 & 2.3 \\
\hline Religious Studies & 4 & 0.7 \\
\hline Sociology & 10 & 1.6 \\
\hline Social Science - Other & 10 & 1.6 \\
\hline Subdiscipline Not Specified & 7 & 1.1 \\
\hline Other & 25 & 4.1 \\
\hline Education & 11 & 1.8 \\
\hline Knowledge Integration & 4 & 0.7 \\
\hline Law & 3 & 0.5 \\
\hline Liberal Arts & 7 & 1.1 \\
\hline
\end{tabular}


Respondents to the survey represented various career stages. When asked how long they had been teaching in higher education, $35.4 \%$ of participants $(n=217)$ indicated they had been teaching for over 20 years, and 12.2\% $(\mathrm{n}=75)$ suggested they had been teaching for fewer than five years. The median response was "11-15 years." Gender representation skewed slightly towards males; 335 respondents (54.6\%) identified as male, $260(42.4 \%)$ identified as female, and one (0.2\%) identified as transgender, while 17 respondents (2.8\%) declined to indicate their gender.

\section{Results}

\section{Defining Creativity}

Although participants offered a wide range of definitions of creativity, many of their responses overlapped with some of the central understandings of the term offered in the literature. For many respondents, for instance, producing something new-whether a product, a theory, or an idea-was one of the defining features of creativity. Along these lines, an individual from the social sciences defined creativity as "[t]he development of novel insights and connections," while a participant from the art/design/performance category suggested that it was "the ability to produce novel solutions to problems." Several participants also emphasized that creative outcomes must be original, unconventional, and/or valuable in addition to being novel. For example, a business faculty member characterized creativity as "the ability to envision and create new things/processes that have aesthetic and/or functional value." A participant from science similarly suggested that creativity is "the ability to transcend traditional boundaries, rules and concepts to develop ideas or products that are new and valuable for society."

Other respondents did not see the creation of a novel product or idea as integral to creativity and instead described the term as a mode of thought or being. Respondents frequently referred to "thinking laterally," "synthetically," or "outside the box," for example, and to open-mindedness or exploration. A humanities respondent offered a definition that included "[t]he ability to think associatively, to make innovative leaps, to take critical risks," for instance, while a faculty member from the health sciences noted that creativity involved "[b]eing mentally flexible and tolerant of ambiguity," as well as "holistic thinking, [the] ability and willingness to look beyond one's expertise in order to find solutions." The distinction between associating creativity with particular ways of thinking and being and defining it as the generation of creative outcomes did not appear to be rooted in specific disciplines; respondents from across fields provided definitions that align with each conception. Likewise, some participants offered answers that indicated agreement with both understandings, suggesting the two are not mutually exclusive.

While these broad conceptions were reported across disciplines, a few participants provided the caveat that they nonetheless viewed their definitions as specific to their fields. For example, one individual described creativity as " $t]$ he capacity to generate new and original insights, perspectives, ideas, interpretations, claims, or concepts" but specified that "[t]his definition is specific to my discipline, philosophy." Another responded as follows: "In my discipline (social sciences), [creativity is] an ability to draw new or insightful connections between social processes, individual behaviour and disciplinary theories. I imagine it would be defined quite differently in different areas." Others offered 
definitions of creativity "in Engineering," "in the Sciences," and "in [the respondent's] profession of medicine." While such disciplinarily framed responses were not common, they do lend initial support to the claim that some individuals perceive their disciplines, and creativity within those domains, as distinctive.

\section{Valuing Creativity}

Across discipline groups, respondents indicated that they value creativity highly. When asked, "How important is creativity to your field?" the overwhelming majority of respondents selected either "important" or "extremely important" $(n=538,87.8 \%)$. A Kruskal-Wallis test indicated a statistically significant difference between the mean responses of the broad discipline areas. The lowest mean reported was from health sciences instructors (4.10), while the highest came from instructors in the "other" category (4.50). It should be noted, however, that the mean response of each discipline was above 4.00 (important), suggesting near-universal recognition among respondents that creativity plays an important role in their disciplines. The overall mean for respondents from all disciplines was 4.22.

A similar pattern of agreement was produced when respondents were asked about their institution's obligations regarding creativity as a learning outcome. Participants were requested to indicate how strongly they agreed with the statement "My department/ school has a responsibility to develop students' creative capacities as these relate to my discipline." A substantial majority of participants selected "agree" or "strongly agree" ( $n$ $=486,79.3 \%)$. Seventeen participants (2.8\%) did not respond to this question. Again, a Kruskal-Wallis test revealed statistically significant differences between the mean responses across disciplines. The lowest means were reported by business and health sciences faculty (3.94 for each group), while the highest came from the "other" category (4.46). The overall mean was 4.07.

In spite of the generally high estimation of creativity indicated in the responses described above, a few unsolicited comments on open-ended questions elsewhere in the survey suggested that some participants have doubts about the relevance of creativity to their fields. A participant from the sciences, for instance, wrote: "Creativity in Physics is a strange topic ... As physicists we often strive to explain that which has already been 'created' in a way, rather than creating ourselves." Similarly, a faculty member from engineering noted, "Engineering is based on incremental improvements. Radical changes are dangerous to the public's safety. Creativity-thinking outside the box-will generally lead to negligence." Responses of this sort, which were admittedly infrequent, were most often provided by respondents from the STEM fields.

The data also indicated some ambivalence about creativity in terms of the position it is afforded in participants' courses and programs. When asked whether the development of students' creativity is a named learning objective in any of the courses they teach, most participants ( $n=338,55.1 \%)$ selected "no," while 207 (33.8\%) selected "yes" and 68 (11.1\%) did not respond. A chi-squared test suggested significant differences between the responses of faculty from various disciplinary categories. The majority of respondents in the other (71.4\%), art/design/performance (68.3\%), and humanities (51.6\%) categories responded positively, while more than two-thirds of those in business (66.7\%), social sciences (70.0\%), and health sciences (78.5\%) responded negatively. When asked whether creativity in their 
discipline was a named outcome for graduating students, only respondents from the other (42.9\%), engineering (42.9\%), and art/design/performance (55.9\%) categories responded in substantial numbers. All other disciplines had selection rates below $25 \%$.

\section{Teaching Creativity}

Participants were asked to declare, on a Likert scale from 1 (strongly disagree) to 5 (strongly agree), how much they agreed with the following statement: "I feel well trained to facilitate student creativity in my discipline." Altogether, the mean response was 3.46. A Kruskal-Wallis test, however, revealed a statistically significant difference between the mean responses of the various disciplines. The range of means extended from 3.09 (health sciences) to 4.15 (art/design/performance). When asked a similar question regarding whether they feel qualified to evaluate students' creativity, participants' responses revealed a similar pattern. A Kruskal-Wallis test again indicated a statistically significant difference, with means ranging from 3.06 (health sciences) to 4.15 (art/design/performance).

A multiple-select question asked participants to indicate techniques that they use to develop students' creativity in their disciplines. Six of the 15 listed techniques were selected by the majority of participants in all major subject groups: "collaborative work/ projects," "encouraging critical thinking," "asking questions/the Socratic method," "incorporating current research/events into lessons and assignments," "challenging students to find new answers to existing problems," and "brainstorming/idea generation." A recurring trend in the results is that several techniques ("describing and emphasizing the importance of creativity to your field," "discussing exemplars of creativity," "reflections/ journaling," and "role modeling creativity") were selected by the majority of respondents in the art/design/performance and "other" categories only. Respondents in different disciplines reported using some techniques to develop students' creativity at very different rates. For example, 60.5\% $(n=46)$ of humanities and 61.9\% $(n=26)$ of art/design/performance faculty selected "rewarding creativity with grades," while only $35 \%(n=49)$ of science and $28.9 \%(n=46)$ of health sciences instructors indicated the same.

Responses to an open-ended follow-up question-which asked participants to indicate which of the techniques they had selected in the previous question had proven effective at fostering students' creativity-suggested that respondents were moderately confident about these strategies overall. For the six techniques selected by the majority of participants in all discipline areas, for example, between 32 and $42 \%$ of individuals who reported using those strategies and responded to the follow-up question suggested that these techniques were effective. Amongst this group of commonly deployed approaches, the strategy described as successful by the highest percentage of people who reported using it was collaborative work (called effective by 150 of 356 , or $42.1 \%$ of relevant respondents). In contrast, incorporating current research/events into lessons/assignments had the lowest rate of perceived success in this group, being named as effective by 115 of 355 of relevant respondents (32.4\%). Some moderate disciplinary variation was again found in these estimations. Only $26.1 \%(n=6)$ of business instructors who reported "encouraging critical thinking" and responded to the follow-up question suggested this technique had worked to develop student creativity, for instance, while $52.9 \%$ of respondents $(n=$ 18) from the art/design/performance group did the same. This difference was significant (according to a chi-squared test) when other disciplinary groups were removed from the 
comparison. Many participants, from across disciplines, noted that the efficacy of given techniques was to some extent dependent on the context (e.g., large vs. small class, undergraduate vs. graduate level), and/or on the individual students in question.

In response to another open-ended question about evidence they had for their claims of efficacy, the vast majority of answering participants $(n=332,72.6 \%)$ suggested that the support was to be found in the creativity of student thinking or outcomes produced in response to these techniques. This claim was made by at least $60 \%$ of responding participants from each major discipline category. Nonetheless, some individuals who answered this question ( $n=68,14.9 \%)$ admitted that they had little to no evidence that their chosen strategies functioned to develop student creativity successfully. This uncertainty was reported by participants in each discipline group but was slightly more common amongst health sciences (21.6\%), engineering (19.6\%), and science (17.5\%) instructors.

When asked how much they agreed with the statement "Students are offered many opportunities to manifest their creativity in my classes," respondents answered strongly in the affirmative, with a mean response of 3.83 on a 5-point scale. However, a KruskalWallis test indicated that the extent of this affirmation varied significantly from discipline to discipline. Instructors from the art/design/performance and "other" categories agreed most strongly with the statement, recording mean ratings of 4.44 in the former case and 4.42 in the latter. In contrast, instructors from the health sciences and sciences agreed less strongly, with means of 3.45 and 3.72, respectively. No group of respondents collectively indicated disagreement with this statement.

\section{Barriers to Creativity}

Participants were asked to respond to another multiple-select question about the barriers that impede the teaching of creativity within their disciplines. Some options were selected at a similar rate across disciplines. The majority $(66.1 \%, n=405)$ of respondents across all subject areas cited time constraints as a major barrier to developing student creativity. Approximately one-third of respondents $(33.1 \%, n=203)$ indicated that they believe there is not enough room in the curriculum to teach creativity, while $38.7 \%$ ( $n=$ 237) suggested they face obstacles in terms of constraints on finances, staffing, equipment, and other resources. Students' attitudes and initiative were cited as a barrier to teaching creativity by $43.6 \%(n=267)$ of respondents.

Selection rates for some other options varied significantly between disciplines. Student preparedness/ability was selected as an obstacle by the majority of respondents teaching in the social sciences (51.4\%) and the humanities $(51.3 \%)$, while those in the other $(20.0 \%)$ and health sciences (32.1\%) categories were less likely to select this as a concern. Relatively large proportions of instructors in health sciences (37.1\%), business (36.4\%), and engineering (34.4\%) selected "the difficulty of assessing creativity," while art/design/performance, social sciences, and humanities instructors did so at much lower rates (9.5\%, 17.6\%, and $19.7 \%$, respectively). $34.6 \%$ of health sciences respondents cited the nature of their discipline as a major barrier, while no other discipline's rate of selection for this item exceeded $22 \%$. 


\section{Discussion}

It should be noted that this study, like any other based on survey research, has its limitations. Our response rate was less than optimal, and the data are likely skewed to some extent due to self-selection bias. It is possible that those instructors who completed the survey view creativity and its place in their teaching differently than do those who were not interested in participating. The grouping of education, law, and interdisciplinary fields for the purposes of analysis is also a limitation, insofar as it might blur important distinctions between these groups. Furthermore, the preponderance of respondents $(59 \%, n=363)$ were instructors in health sciences, sciences, or engineering. This demographic information should be kept in mind when interpreting this paper's results. Nevertheless, in tandem with the generally high valuation of creativity reported by participants in this study, this concentration of respondents from STEM fields might itself be seen as an interesting finding, given that it runs somewhat counter to the expected connection between creativity and the arts and humanities (Glăveanu, 2014) and echoes recent research (e.g., DeHaan, 2009; Walsh et al., 2013) in suggesting that some STEM scholars, at least, see creativity as significant to their fields.

The present research offers some other valuable insights as well, especially when examined in relation to the results of the pilot study conducted by the authors on the same subject (2012). Notably, both datasets reveal a discrepancy between how much instructors value creativity and the extent to which they focus explicitly on its development in their teaching. While it appears creativity is often understood as important to academic fields, and while many instructors agree that their institutions have a responsibility to develop students' creative capacities, creativity is less frequently named as an official learning outcome in courses and programs across disciplines. In this respect, the present study corroborates claims made elsewhere about the limited extent to which considerations of creativity figure actively in courses and curricula (e.g., Jackson, 2008; Jackson \& Shaw, 2006), and it highlights a specific gap that needs to be addressed in order to more effectively develop creativity in Ontario's students.

John Biggs's principle of constructive alignment, which was discussed in our pilot study, further emphasizes the importance of addressing this discrepancy. The practice of constructive alignment requires that "all components in the teaching system-the curriculum and its intended outcomes, the teaching methods used, the assessment tasks-are aligned to each other" (Biggs, 2003, p. 1). In other words, constructive alignment dictates that courses and curricula be designed with explicit end goals in mind, and that all components of the learning experience be conceived so as to contribute to the realization of those goals. When this happens, enhanced learning is understood to result. With this in mind, given that our data suggest that creativity is named as a learning outcome relatively rarely in Ontario universities, the extent to which courses and programs can effectively promote its development is compromised. If, on the other hand, creativity were expressly recognized by instructors as an intended outcome, this sentiment was communicated directly to students, and courses and programs were designed consciously to elicit and assess creativity, creative outcomes might, in turn, be improved. Addressing the gap noted in our data, then, could have impacts that are more than cosmetic. 
In addition to pointing to this general imperative, this study has also revealed some prevalent attitudes with respect to creativity among university instructors from a wide range of fields, contributing to the discussion about the role of disciplines in developing student creativity. In some regards, our findings corroborate the argument that the significance of discipline can be overstated in considerations of teaching and learning, as articulated, for example, by Wareing (2009) and Young (2010), and as discussed in relation to creativity specifically by Fryer (2006). Much like the participants described by Edwards, McGoldrick, and Oliver (2006), respondents across fields in the current survey defined creativity in ways that often overlapped substantially with one another, and positioned creativity as important to academic work across domains. These participants also reported using a number of shared strategies to develop creative abilities in their students (e.g., collaborative work, idea generation, challenging students to find new answers to existing problems), some of which have likewise been positioned as at least somewhat effective in discipline-generic creativity scholarship (Baillie, 2006; Fryer, 2006; Paulus, 2000). The potential for significant overlap between disciplinary teaching and learning contexts was also indicated in the finding that certain barriers to teaching creativity (most notably, time constraints and student attitudes) were perceived as relevant by participating faculty from all disciplines.

Nonetheless, these data also suggest a number of respects in which instructors from various disciplines appear to differ in their understandings of creativity and its place in their teaching. Echoing scholars who argue that even generic views of creativity are necessarily actualized within specific fields (e.g., Jackson \& Shaw, 2006; Reid \& Petocz, 2004), some participants in the present study framed their definitions of the term in ways that connected broadly described attributes to particular disciplinary contexts. Likewise, in spite of the general consensus in the data that creativity is significant across fields and ought to be developed in all students, a number of the findings indicate that it might nonetheless be seen by the survey participants as slightly less central to STEM disciplines than it is to the arts and humanities.

Instructors from the health sciences consistently responded less positively on questions designed to assess the perceived value of creativity within disciplines, for instance, and also cited the nature of their disciplines as a barrier to developing students' creative capacities far more frequently than did respondents from other fields. In open-ended questions, a small number of participants from engineering and science likewise articulated concerns that creativity was incompatible with the scientific methods central to their disciplines, repeating perspectives articulated in recent STEM-focused research (Walsh et al., 2013). Health sciences faculty members were also substantially less likely to agree that they felt well trained to facilitate or to assess student creativity than were respondents in the art/design/performance category, and participants from science and health sciences agreed less strongly than respondents from the arts that students are given many opportunities to manifest creativity in their courses. Taken together, these findings suggest that instructors in the STEM disciplines may to some extent be feeling the impacts of the "art bias" described in the creativity literature (Glăveanu, 2014), in spite of pushing against that bias in many ways. Even as the present data convey widespread agreement that creativity is an essential aspect of scientific fields, for instance, a sense remains that some individuals understand it as at least partially opposed to scientific thinking. Like- 
wise, perhaps as a result of this view and its impact on disciplinary cultures, some STEM faculty appear to feel less inclined or able to develop creativity in their students than their counterparts in other fields. In light of this distinctive set of tensions, domain-specific training opportunities that provide STEM instructors with opportunities to define, discuss, and learn about the teaching of scientific creativity might be an essential part of enhancing teaching for creativity in these fields.

In addition to highlighting these potential differences in the positioning of creativity across domains, the findings reported here also point toward a number of respects in which different academic fields may vary in their creativity-related teaching techniques. Respondents affiliated with different subject areas reported using some strategies to foster their students' creative development at differing rates. For example, those groups that reported naming the development of creativity as an explicit learning outcome most frequently (i.e., the "art/design/performance" and "other" categories) also reported using a number of teaching strategies that were not commonly cited by participants in other fields (e.g., discussing exemplars of creativity, modelling creative practices, reflection). Together, these trends might be taken to suggest that instructors in these categories have been engaging in constructive alignment practices, as they name the development of creativity as a learning goal and engage in a wide variety of activities designed to aid in this development. Notably, the majority of participants in these fields also reported "rewarding creativity with grades." Despite often being positioned in the literature as less effective than encouraging internal motivation (Beghetto, 2010; Prabhu, Sutton, \& Sauser, 2008), this strategy might nonetheless be taken as a further indication of alignment, insofar as it implies that creativity is being explicitly assessed by these instructors.

In addition to suggesting that creativity may often be taught somewhat differently within fields like art and design than it is in others (corroborating claims of disciplinary difference), these findings might also be taken, somewhat paradoxically, as suggestive of ways in which teaching for creativity can be enhanced in other fields. Given the theoretical connection between constructive alignment and enhanced outcomes, and the fact that instructors in art, design, and performance also reported in this study a comparatively high degree of confidence in their abilities to teach and assess creativity, it seems reasonable to infer that, on average, instructors in these fields might be especially effective at facilitating creativity in their students (although this assertion demands further empirical support). To the extent that this is true, it may be worth assessing how far techniques used by instructors in these disciplines can be adapted effectively to other teaching and learning contexts. Along these lines, some existing literature suggests that strategies used in art and design education might serve as useful exemplars for individuals looking to develop student creativity in other subject areas (Dineen, 2006).

Of course, however, the question remains as to whether these strategies are more common to teaching in art, design, and related areas because individuals from other fields have not yet discovered them, or because the strategies are indeed discipline-specific. There is also the issue of whether these techniques will be equally effective across domains even if they can be used widely. On this note, the present research offers a range of provocative suggestions. On the one hand, the fact that respondents from different fields reported particular techniques to be effective at different rates (e.g., the discrepancy between instructors in business and in art/design/performance as to the perceived 
efficacy of encouraging critical thinking) indicates that some people at least believe given techniques to be differentially useful in their specific contexts. At the same time, it is also true that when respondents from disciplines outside of the arts reported using techniques common to arts fields, they sometimes also suggested that these strategies were successful at developing students' creativity in their own disciplines. While only small numbers of science and engineering faculty reported modelling creativity as a strategy for fostering students' creative abilities, for instance, nearly $50 \%$ of participants who did note using this technique (46.7\% of respondents in each of the two discipline groups) claimed that it had proven effective. It should also be noted that this strategy has been advocated in the literature as a generic means of fostering creativity (Jackson \& Sinclair, 2006), providing further support for claims of transferability. In light of this range of findings, and the fact that our survey could in any case only collect evidence of perceived success, the actual efficacy of particular creativity teaching strategies within various disciplinary contexts requires further research.

\section{Conclusion}

Taken together, the findings of this study indicate that there are a number of distinctions between disciplines in terms of instructors' perceptions of and strategies for developing student creativity. Nonetheless, the data also reveal that disciplinary distinctions can sometimes be fuzzy where the teaching of creativity is concerned, as some strategies appear to cut across domains already and others may be ripe for adaptation. With this in mind, potential programs designed to assist faculty in teaching for creativity ought to be focused on and tailored to disciplinary contexts without being limited to them; discipline-local "teaching and learning regimes" (Trowler, 2008) should be acknowledged and accounted for as Jackson (2006) suggests, but opportunities to connect disciplinary or departmental discourses with findings about creativity from other fields should also be explored. Drawing from the results reported here, future research could involve the creation of professional development programs related to teaching creativity in specific disciplines, followed by an empirical assessment of their efficacy. Given our findings demonstrating potential tensions related to creativity in STEM fields, these disciplines might be a fruitful place to begin such work. At the same time, additional studies might focus on adapting creativity teaching strategies such as those commonly reported by instructors in the art/design/performance and "other" categories to different contexts and evaluating their success. Work along either of these lines would further contribute to the discipline-specific/disciplinegeneric pedagogy debate while simultaneously benefitting both faculty and students.

As mentioned in the introduction of this paper, the demands placed on today's university graduates by the reality of a globalized economy will require them to be innovative, critically thinking problem solvers. Far from being an extra skill that students can develop at their leisure, creativity has become central to success in careers across the disciplinary spectrum. However, economic incentives and student employability should not be the only factors motivating a focus on developing creativity in higher education. Progress within academic disciplines requires practitioners who are able to use existing ideas in creative ways to generate new knowledge and contribute to their discipline's scholarship. Invariably and inevitably, these practitioners will be a product of the current university system. Creativity is thus vital to the interests of academia regardless of discipline, and further research is warranted to ensure that educators are promoting it using the best available practices. 


\section{Notes}

1 It should be noted that throughout this article, we are using the term "teach" in a manner that aligns with long-standing constructivist conceptions of teaching as the facilitation of student learning and development (King, 1993).

\section{Acknowledgements}

The authors wish to acknowledge the innumerable contributions to this work of Susan Vajoczki, who collaborated actively on this project until her untimely death in 2012. We also wish to thank all of our survey participants for sharing their time and ideas.

\section{References}

Åkerlind, G. S. (2005). Academic growth and development: How do university academics experience it? Higher Education, 5o(1), 1-32.

Baillie, C. (2006). Enhancing students' creativity through creative-thinking techniques. In N. Jackson, M. Oliver, M. Shaw, \& J. Wisdom (Eds.), Developing creativity in higher education (pp. 142-155). New York, NY: Routledge.

Beghetto, R. A. (2010). Creativity in the classroom. In J. C. Kaufman \& R. J. Sternberg (Eds.), The Cambridge handbook of creativity (pp.447-466). Cambridge, UK: Cambridge University Press.

Biggs, J. (2003). Aligning teaching for constructing learning. York, UK: Higher Education Academy. Retrieved from https://www.heacademy.ac.uk/aligning-teachingconstructing-learning

Brew, A. (2008). Disciplinary and interdisciplinary affiliations of experienced researchers. Higher Education, 56(4), 423-438.

Craft, A. (2006). Fostering creativity with wisdom. Cambridge Journal of Education, 36(3), 337-350.

Csikszentmihalyi, M. (1999). A systems perspective on creativity. In R. Sternberg (Ed.), Handbook of creativity (pp. 313-335). Cambridge, UK: Cambridge University Press.

Csikszentmihalyi, M. (2006). Foreword: Developing creativity. In N. Jackson, M. Oliver, M. Shaw, \& J. Wisdom (Eds.), Developing creativity in higher education (pp. xviii-xx). New York, NY: Routledge.

DeHaan, R. L. (2009). Teaching creativity and inventive problem solving in science. CBE - Life Sciences Education, 8(3), 172-181.

Dineen, R. (2006). Views from the chalk face: Lecturers' and students' perspectives on the development of creativity in art and design. In N. Jackson, M. Oliver, M. Shaw, \& J. Wisdom (Eds.), Developing creativity in higher education (pp. 109-117). New York, NY: Routledge.

Edwards, M., McGoldrick, C., \& Oliver, M. (2006). Creativity and curricula in higher education: Academics' perspectives. In N. Jackson, M. Oliver, M. Shaw, \& J. Wisdom (Eds.), Developing creativity in higher education (pp. 59-73). New York, NY: Routledge. 
Fanghanel, J. (2013). Going public with pedagogical inquiries: SoTL as a methodology for faculty professional development. Teaching and Learning Inquiry, 1(1), 59-70.

Fryer, M. (2006). Facilitating creativity in higher education: A brief account of National Teaching Fellows' views. In N. Jackson, M. Oliver, M. Shaw, \& J. Wisdom (Eds.), Developing creativity in higher education (pp. 74-88). New York, NY: Routledge.

Glăveanu, V. P. (2014). Revisiting the "art bias" in lay conceptions of creativity. Creativity Research Journal, 26(1), 11-20.

Healey, M. (2000). Developing the scholarship of teaching in higher education: A discipline-based approach. Higher Education Research \& Development, 19(2), 169-189.

Henkel, M. (2005). Academic identity and autonomy in a changing policy environment. Higher Education, 49(1-2), 155-176.

Jackson, N. (2006). Making sense of creativity in higher education. In N. Jackson, M. Oliver, M. Shaw, \& J. Wisdom (Eds.), Developing creativity in higher education (pp. 197-215). New York, NY: Routledge.

Jackson, N. (2008). Tackling the wicked problem of creativity in higher education. Retrieved from http://www.normanjackson.co.uk/creativity.html

Jackson, N., \& Shaw, M. (2006). Subject perspectives on creativity. In N. Jackson, M. Oliver, M. Shaw, \& J. Wisdom (Eds.), Developing creativity in higher education (pp. 89-108). New York, NY: Routledge.

Jackson, N., \& Sinclair, C. (2006). Developing students' creativity: Searching for an appropriate pedagogy. In N. Jackson, M. Oliver, M. Shaw, \& J. Wisdom (Eds.), Developing creativity in higher education (pp. 118-141). New York, NY: Routledge.

Kaufman, J. C., \& Baer, J. (Eds.) (2005). Creativity across domains: Faces of the muse. Mahweh, NJ: Lawrence Erlbaum.

King, A. (1993). From sage on the stage to guide on the side. College Teaching, 41(1), 30-35.

Kleiman, P. (2008). Towards transformation: Conceptions of creativity in higher education. Innovations in Education and Teaching International, 45(3), 209-217.

Lindblom-Ylänne, S., Trigwell, K., Nevgi, A., \& Ashwin, P. (2006). How approaches to teaching are affected by discipline and teaching context. Studies in Higher Education, 31(3), 285-298.

Manathunga, C. (2006). Doing educational development ambivalently: Applying postcolonial metaphors to educational development? International Journal for Academic Development, 11(1), 19-29.

Marquis, E., \& Vajoczki, S. (2012). Creative differences: Teaching creativity across the disciplines. International Journal for the Scholarship of Teaching and Learning, 6(1). Retrieved from http://digitalcommons.georgiasouthern.edu/ij-sotl/vol6/iss1/6/

Mårtensson, K., Roxå, T., \& Olsson, T. (2011). Developing a quality culture through the scholarship of teaching and learning. Higher Education Research \& Development, $30(1), 51-62$. 
McLean, J. (2009). Triggering engagement in SoTL through threshold concepts. International Journal for the Scholarship of Teaching and Learning, 3(2). Retrieved from http://digitalcommons.georgiasouthern.edu/ij-sotl/vol3/iss2/24/

McWilliam, E. (2008). The creative workforce: How to launch young people into high-flying futures. Sydney, Australia: UNSW Press.

Merriam, S. B. (2009). Qualitative research: A guide to design and implementation (3rd ed.). San Francisco, CA: Jossey-Bass.

Mumford, M. D. (2003). Where have we been, where are we going? Taking stock in creativity research. Creativity Research Journal, 15(2-3), 107-120.

Neumann, R., Parry, S., \& Becher, T. (2002). Teaching and learning in their disciplinary contexts: A conceptual analysis. Studies in Higher Education, 27(4), 405-417.

OCAD University. (2013). History. Retrieved from http://www.ocadu.ca/about_ocad/ overview/historical_summary.htm

Oliver, M., Shah, B., McGoldrick, C., \& Edwards, M.. (2006). Students' experiences of creativity. In N. Jackson, M. Oliver, M. Shaw, \& J. Wisdom (Eds.), Developing creativity in higher education (pp. 43-58). New York, NY: Routledge.

Ontario Ministry of Training, Colleges, and Universities. (2012). Strengthening Ontario's centres of creativity, innovation, and knowledge. Ottawa, ON: Queen's Printer for Ontario. Retrieved from http://www.tcu.gov.on.ca/pepg/publications/ DiscussionStrengtheningOntarioPSE.pdf

Paulus, P. B. (2000). Groups, teams, and creativity: The creative potential of ideagenerating groups. Applied Psychology: An International Review, 49(2), 237-262.

Petocz, P., Reid, A., \& Taylor, P. (2009). Thinking outside the square: Business students' conceptions of creativity. Creativity Research Journal, 21(4), 409-416.

Plucker, J. A., \& Makel, M. C. (2010). Assessment of creativity. In J. C. Kaufman \& R. J. Sternberg (Eds.), The Cambridge handbook of creativity (pp. 48-73). Cambridge, UK: Cambridge University Press.

Prabhu, V., Sutton, C., \& Sauser, W. (2008). Creativity and certain personality traits: Understanding the mediating effect of intrinsic motivation. Creativity Research Journal, 2O(1), 53-66.

Reid, A., \& Petocz, P. (2004). Learning domains and the process of creativity. The Australian Educational Researcher, 31(2), 45-62.

Roxå, T., \& Mårtensson, K. (2008). Teaching and learning regimes from within: Significant networks as a locus for the social construction of teaching and learning. In C. Kreber (Ed.), The university and its disciplines: Teaching and learning within and beyond disciplinary boundaries (pp. 209-218). New York, NY: Routledge.

Seltzer, K., \& Bentley, T. (1999). The creative age: Knowledge and skills for the new economy. London, UK: Demos.

Shaheen, R. (2010). Creativity and education. Creative Education, 1(3), 166-169. 
Smith-Bingham, R. (2006). Public policy, innovation and the need for creativity. In N. Jackson, M. Oliver, M. Shaw, \& J. Wisdom (Eds.), Developing creativity in higher education (pp. 10-18). New York, NY: Routledge.

Trowler, P. (2008). Beyond epistemological essentialism: Academic tribes in the twenty-first century. In C. Kreber (Ed.), The university and its disciplines: Teaching and learning within and beyond disciplinary boundaries (pp. 181-195). New York, NY: Routledge.

Trowler, P. (2013). Depicting and researching disciplines: Strong and moderate essentialist approaches. Studies in Higher Education, 1-12. doi:10.1080/03075079.20 13.801431

Walsh, E., Anders, K., Hancock, S., \& Elvidge, E. (2013). Reclaiming creativity in the era of impact: Exploring ideas about creative research in science and engineering. Studies in Higher Education, 38(9), 1259-1273.

Wareing, S. (2009). Disciplines, discourse and Orientalism: The implications for postgraduate certificates in learning and teaching in higher education. Studies in Higher Education, 34(8), 917-928.

Young, P. (2010). Generic or discipline-specific? An exploration of the significance of discipline-specific issues in researching and developing teaching and learning in higher education. Innovations in Education and Teaching International, 47(1), 115-124.

Zacher, H., \& Johnson, E. (2014). Leadership and creativity in higher education. Studies in Higher Education. doi:10.1080/03075079.2014.881340

\section{Contact Information}

Elizabeth Marquis

Arts \& Science Program

McMaster University

beth.marquis@mcmaster.ca

Elizabeth Marquis is an assistant professor in the arts and science program and the School of the Arts at McMaster University. Her teaching and learning research focuses on film studies pedagogy, the accessibility of higher education for students with disabilities, and the teaching and learning of creativity across disciplines. Her work in these areas has been published in journals such as The International Journal for the Scholarship of Teaching and Learning and The Canadian Journal for the Scholarship of Teaching and Learning.

Jeremy A. Henderson is a recent graduate of the arts and science program at McMaster University, where he earned an honours bachelor of arts and science and political science in 2013. He has been involved in a number of teaching and learning research projects at the McMaster Centre for Leadership in Learning and the Higher Education Quality Council of Ontario, including work devoted to inclusive and accessible education and to fostering international collaborations in the scholarship of teaching and learning. He is currently studying at the University of Victoria's Faculty of Law. 